\title{
Geomorphic modelling for small watersheds using Principal Component Analysis
}

Sandip Nikam

Received : 10.01.2020; Revised : 15.02.2020; Accepted : 01.03.2020

Author for Correspondence:

Sandip Nikam

Department of Agricultural

Engineerng, College of Agriculture (MPKV), Dhule

(M.S.) India

Email:spnikam74@gmail.com
-ABSTRACT : Principal Component Analysis was carried out for grouping the different parameters into the Principal Components. To understand the behaviour of all the parameters pertaining to study areas, and to reduce the dimensionality of database, the data pertaining to twelve parameters of ten small watersheds were submitted for Principal Component Analysis. The method of components analysis, then, involves the rotation in the total variable space - an orthogonal or uncorrelated transformation wherein each of the $n$ original variables is describable, in terms of the n new principal components. An important feature of the new components is that they account, in turn, for a maximum amount of variance of the variables. Analysis extracted three components as a Principal Components with 10 parameters, accounting for a total variance of 97.256 per cent. The first component is highly correlated with $\mathrm{R}_{e}, \mathrm{R}_{\mathrm{c}}, \mathrm{S}_{\mathrm{b}}$ and $\mathrm{L}_{\mathrm{bw}}$ accounting for 68.52 per cent variance. Second component is strongly correlated with $\mathrm{R}_{\mathrm{N}}$ accounting for 18.60 per cent variance and Third with $\mathrm{S}_{\mathrm{c}}$, accounting for 10.13 per cent variance. Finally, these extracted 10 parameters were used for modeling for prediction of sediment yield and runoff from selected small watersheds of Tapi basin, Maharashtra, India.

- KEY WORDS : Principal Component analysis, Geomorphological parameters, Morphometric model, Small watersheds

-HOW TO CITE THIS PAPER : Nikam, Sandip (2020). Geomorphic modelling for small watersheds using Principal Component Analysis. Internat. J. Agric. Engg., 13(1) : 62-66, DOI: 10.15740/ HAS/IJAE/13.1/62-66. Copyright@2020: Hind Agri-Horticultural Society. 